\title{
Research on the Mode of Innovation and Entrepreneurship Education for College Students
}

\author{
Di Jiang and Zhenlai Hou
}

\begin{abstract}
At present, China's economic development and social progress are inseparable from scientific and technological innovation, so the cultivation of innovative talents in colleges and universities is crucial. This paper explores the mode of innovation and entrepreneurship education in colleges and universities under the background of Internet. Starting with the elaboration of the connotation and mode of "Internet + education", this paper further analyzes the existing problems of innovation and entrepreneurship education in colleges and universities in China, and finally puts forward the key points of development of innovation and entrepreneurship education in colleges and universities under the background of Internet.
\end{abstract}

Index Terms-Internet, college innovation and entrepreneurship education mode, connotation, there are problems, focus.

\section{INTRODUCTION}

"Internet + education" is a kind of new education form, is not only the Internet, mobile Internet technology application in education, or use the Internet technology to build all kinds of education, learning platform, and it is the depth of the Internet, mobile Internet and education, is to promote education progress, improve efficiency and organizational change, strengthen the education of innovation and productivity has strategic and the overall education reform.

In the current environment of "Internet + education", the curriculum of innovation and entrepreneurship education in colleges and universities also needs to be reformed and innovated, and the educational concept needs to be transformed into educational practice by relying on effective curriculum carriers. However, the key to realize innovation and entrepreneurship curriculum reform and innovation is the construction of curriculum system, which promotes the development of innovation and entrepreneurship education in colleges and universities by constantly strengthening the construction of curriculum system. Due to the current domestic colleges and universities in the innovation and entrepreneurship education work, there are problems such as teachers and students innovation and entrepreneurship education thought understanding is not in place, the lack of teachers, teaching process is not continuous, and so on, which has a negative impact on the development of education. Colleges and universities need to focus on this to solve problems and improve the quality of education. In addition,

Manuscript received March 18, 2019; revised July 3, 2019. This work was supported in part by Jilin Education Department and Jilin Education Science Leading Group.

The authors are with School of Municipal and Environmental Engineering, Jilin Jianzhu University, China (e-mail: Jiangdi511@163.com, 1461319255@qq.com). nnovative talents of science and technology should have comprehensive analysis ability, innovation ability and the ability to solve practical problems, therefore, in training talents in colleges and universities should put emphasis on the theoretical basis and practical application ability, have basic knowledge and high comprehensive quality, strong practical ability and enterprise technology innovation in the field of science and technology in the interdisciplinary talents has a competitive advantage.

\section{INNOVATION AND ENTREPRENEURSHIP EDUCATION AT HOME AND ABROAD DEVELOPMENT STATUS}

Innovation and entrepreneurship education in Europe and the United States and other developed countries has been highly valued, not only the development is very mature, but also quite a large scale. The United States, Britain, Australia and other countries of the innovative undertaking education relative to the our country already has several decades of development history, their innovative entrepreneurial process as the core, build a complete education curriculum system from inside to outside, made a pioneering idea, the spirit of adventure, with many pioneering consciousness and ability of work independence creative and pioneering talents. Entrepreneurship education in developed countries has shown some characteristics, such as continuity from survival to development, extension from stage education to lifelong education, expansion from economic field to cultural field, and refinement from macro content. From the height of scientific understanding of innovation and entrepreneurship, they promote the whole economic development, scientific and technological progress and the pace of social entrepreneurship, highlighting the characteristics of social welfare.

The actual current situation of development of creative education in China, the total percentage of college students' innovative undertaking is far from up to $1 \%$ of the total number of the graduates entrepreneurship is far lower than the global average innovation entrepreneurship monitor (GEM) statistical average, due to the particularity of the development process of Chinese history, economic system and structure, social and public environment, the understanding of the education and philosophy, teaching resources and model, and many other restriction conditions, only part of the students in colleges and universities accept entrepreneurship education innovation, and the education system is not perfect, therefore, innovative entrepreneurship education start stage in our country [1]. How to accelerate the transformation of the mode of economic development; How to deepen the comprehensive reform of higher education 
teaching; How to improve the quality of talents; How to promote the overall development of students; How to implement innovation and entrepreneurship to drive employment, a series of problems are a profound warning of China's innovation and entrepreneurship education curriculum reform. The main reason why Chinese universities should carry out innovation and entrepreneurship education in depth is that, in the final analysis, no matter from which perspective, innovation and entrepreneurship education is to meet the needs of different subjects. The transformation of the economic development pattern depends on innovation and entrepreneurship activities, encouraging innovation and entrepreneurship, promoting entrepreneurship to drive employment, implementing the employment priority strategy, and supporting youth entrepreneurship. The decision of the central committee of the communist party of China (CPC) on several major issues concerning comprehensively deepening reform, released later, once again puts forward the following new mechanisms government incentives for entrepreneurship, social support for entrepreneurship, and workers' courage to start businesses. It has become a new trend of education reform and development all over the world to strengthen the management of innovation and entrepreneurship education so as to better reform the talent training mode of innovation and entrepreneurship education.

\section{CONNOTATION AND MOdE OF "INTERNET + EdUCATION"}

The essence of "Internet plus" is the high integration of informatization and industrialization. It is based on big data and the Internet. It integrates the Internet with other industries and complements each other to fully integrate the business opport unities and advantages of the Internet and various industries. In modem society, informatization has become an important trend in the development of various industries. Enterprises actively and independently introduce the Internet, and can take advantage of the Internet to reform and innovate the traditional business forms and industrial development models, such as gradually transforming customers into users of various software and apps. The Internet system is rich in resources, and the commercial operation of it is also an important channel to realize the value of the Internet itself. In a word, the existence of "Internet+" mode creates a carrier of efficient operation for the sharing and utilization of resources and information, which can realize the full utilization of resources and overall improvement of resources and oerrall improverment of work efficiency. "Internet + education" is to use multimedia technology to develop a new type of education form, such as the Internet, is based on Internet technologies to learners as the main body of education, in it, students and teachers, students and education institutions between the main use of the Internet media to establish a variety of interactive methods, thus systematic education and communication connection, reflect is a kind of "Human - machine - content ternary interconnected relations" (Human - Cyber - Physical). At the same time, "it also reflects the innovation of the whole and part of education with Internet thinking, so as to make a qualitative change in education and achieve a certain level of leap". Through the support of technology for education innovation, it promotes the development of education crowd innovation space and truly realizes the openness and innovation of sharing education.

"Internet + education" is of great significance and value in line with the current era. The construction and development of "Internet + education" are the same as the realization of educational informationization goals, and there is a wealth of value pursuit in the process. From the history of Internet development in developed countries, we can see that the interpretation of "Internet + education" should be based on its social and individual functions. In other words, it should not only reveal the external social, economic and cultural environment where "Internet + education" is located, but also reflect the rules of teachers, students and school management within "Internet + education".

China's "Internet + education" has the same value pursuit as developed countries, which is not only an important deployment of "network education" and "talent development", but also an important condition for forming a learning society and realizing lifelong learning and self-development for all. However, based on the actual differences of local education, "Internet + education" has its unique significance and value in China.

\section{PROBlems In INNOVATION AND ENTREPRENEURSHIP EDUCATION}

\section{A. Insufficient Understanding of Innovation and Entrepreneurship Education Thoughts}

In the Internet era, to develop the cause of innovation and entrepreneurship education, we must first help college students change their ideas and form a correct sense of innovation and entrepreneurship. But many colleges and universities, the leadership of the teach understanding of innovative undertaking profound enough, simply be included in the field of education, still adopts the method of general education in order to develop entrepreneurship education work, one-sided teaching will focus on strengthening the students' ability of entrepreneurship, and failed to students seeking truth from facts to self-employment in practice. Many teachers teach according to the textbook content completely, fail to combine it with practice, and fail to contact with other auxiliary subjects, resulting in students' little contact with practical technology, weak theoretical grasp, limited knowledge, and inability to adapt to the requirements of innovation and entrepreneurship in a complex environment.

\section{B. Lack of Teachers for Innovation and Entrepreneurship Education}

Compared with the mode of entrepreneurship education in many developed countries, the faculty of entrepreneurship education in colleges and universities is insufficient in strength and the professional structure is unreasonable, which cannot provide effective support for the smooth development of teaching work. In addition, many teachers do not have the experience of business practice and only have 
the basic theoretical knowledge. In teaching, the form is often more simple, and the elaboration is not thorough enough. In contrast, the entrepreneurship education teachers in developed countries are composed of professional professors, successful entrepreneurs and government officials. They are more professional, have rich practical experience and have a deeper understanding of the operating principles and industrial rules of enterprises [2]. This objective gap must be addressed through effective measures.

\section{Abbreviations and Acronyms}

Since the innovation and entrepreneurship education in domestic colleges and universities has not been developed for a long time, it is not mature enough in terms of teaching contents and methods, and the entrepreneurship education in colleges and universities is not perfect enough. It is precisely because of the lack of originality and systematicness of the teaching content and methods that the continuity of the teaching process is destroyed. Many universities do not offer formal courses on innovation and entrepreneurship, and students can only learn relevant knowledge by participating in relevant lectures and competitions. Although some universities do offer courses on innovation and entrepreneurship, they are only limited to the teaching of basic theoretical knowledge. Other practices are not extended enough, and the teaching effect is not excellent. For example, the entrepreneurship training program is mainly about SYB, SIYB and KAB training, and the teaching practice includes organizing students to participate in entrepreneurship training and innovation and entrepreneurship design competition [3]. However, there is still a big gap between the teaching content and this program.

\section{Explore the CREATIVE EdUCATION PATTERN IN COLLEGES AND UNIVERSITIES}

\section{A. Establish the New Concept of "Internet + "Innovation and Entrepreneurship Education}

The wide application of Internet technology in people's life and production has changed the traditional behavior and way of thinking. However, due to the solid foundation of traditional concepts and models in the field of education, the breakthrough in the modernization of education has been greatly hindered. To play to the role of the Internet in the field of creative education, the first thing to update the concept of school administrators and teachers and students, the architecture of a new type of level teaching management structure, to schools, colleges, students and other factors are fully integrated and comprehensive utilization, according to the different characteristics of each school, college, students, targeted to the popularization of Internet knowledge, knowledge of universal access to the Internet, and by using the information technology innovation entrepreneurship education for publicity, carry out the work of education thought barrier.

\section{B. Improve the "Internet $+"$ Entrepreneurship Education Courses}

Due to the unscientific setting of entrepreneurship education courses, inaccurate positioning of some training courses and the failure to combine the teaching practice of domestic colleges and universities, many schools set up subjects that meet the characteristics of China's market environment and students' learning needs, and simply copy the curriculum model of developed countries, which is difficult to be quickly accepted by students. Under the new situation, schools should constantly improve the "three-dimensional" innovation and entrepreneurship education model, and reasonably set courses in combination with the actual situation of schools. For the freshmen, the basic courses of entrepreneurship education should be mainly taught, and the teaching should be guided step by step from helping students to set up correct concepts. For sophomore students, they can explain some deeper and more difficult knowledge and technology. For junior and senior students, the school can organize students to go to the enterprise and entrepreneurship base for field observation and practical practice.

Build an innovation and entrepreneurship education curriculum system that is organically integrated with professional education and matched with innovative talents. Only through the core link of curriculum can we achieve the goal of cultivating innovative talents, and whether the goal can be achieved depends on the progress of curriculum reform, which determines the basic direction of talent training in colleges and universities. To set up the curriculum system of innovation and entrepreneurship education, we should first dilute the boundaries of disciplines and pay attention to the interpenetration and intersection of disciplines. Secondly, we should pay attention to the practicability and innovation of innovation and entrepreneurship education. Finally, we should establish our own unique and relatively sound curriculum system of innovation and entrepreneurship based on the regional reality.

\section{Build a Practical System of Innovation and Entrepreneurship Education}

A practical system for college students' innovative undertaking education refers to the creative education to create a distinguished, from simple to complex system teaching and activities, and through this system, the professional teaching activities, social practice, practice activities, scientific research activities, entrepreneurship practice activities together, forming gradually the whole process of entrepreneurship training. The realization of college students' innovation and entrepreneurship education practice system is mainly realized by integrating various resources of schools, enterprises and society, and establishing open and diversified entrepreneurship practice platform and base. According to the characteristics of innovation and entrepreneurship practice teaching, the author divides innovation and entrepreneurship practice system into cognitive innovation and entrepreneurship practice, reflective innovation and entrepreneurship practice, simulation innovation and entrepreneurship practice.

First, cognitive innovation and entrepreneurship practice: Organize students to participate in social practice and social investigation activities, so as to deeply understand the society, understand the current situation and development of 
enterprises, and improve their cognitive ability; Guide students to make full use of course practice and graduation practice, contact with professional practice activities, and improve professional innovation and entrepreneurship ability; Guide students to experience enterprise management and corporate culture in the internship and training base, and improve management innovation and entrepreneurship ability.

Second, Give full play to the exemplary role of outstanding graduates in innovation and entrepreneurship and the incentive role of successful cases, or use lectures and symposiums to educate and guide students, enrich students' knowledge and experience of innovation and entrepreneurship, or use interviews to contact, feel and learn typical models, so as to improve the passion and ability of innovation and entrepreneurship.

Third, through holding innovation and entrepreneurship competition, the school guides students to participate in various scientific research training activities, and carries out innovation and entrepreneurship education. In particular, comprehensive and designed scientific research training activities enable students to stimulate entrepreneurial awareness, experience entrepreneurial experience, enhance communication and cultivate team spirit in the training competition. We regularly carry out scientific and technological innovation activities such as lectures on innovation and entrepreneurship skills, academic weeks and science and technology months, and provide financial support and innovative experimental platforms for students' scientific and technological innovation projects by setting up research and innovation funds.

\section{Strengthen the Construction of "Internet +" Entrepreneurship Education Faculty}

Due to the shortage of teachers and unreasonable teacher structure in many colleges and universities in China, the progress of entrepreneurship education has been hindered. Therefore, it is very necessary to strengthen the teachers and improve the level of teachers. Considering that many teachers have never been deeply exposed to the Internet industry and have insufficient understanding of the characteristics of entrepreneurship education in the era of mobile Internet, some teachers lack practical experience and cannot explain knowledge with empathy. Based on its own development needs, the school should establish the "first-level and second-level" entrepreneurship mentor mode, constantly introduce high-level innovative and entrepreneurial talents to play a leading role in the school and guide the smooth development of innovation and entrepreneurship work of the whole school. Of course, the school can also strengthen the rational allocation of existing resources and make full use of them, so that students with practical experience in entrepreneurship can impart their personal experience and help students make progress together. At the same time, the school can invite successful businessmen and education experts outside the school to provide intellectual support for the school, and establish an "online + offline" elite tutor team to escort students to learn innovation and entrepreneurship knowledge.

\section{E. Improve the Establishment of "Internet+" Entrepreneurship Practice Platform}

In the new era of "Internet + ", schools need to build a "trinity" education model. Starting from the idea of "theoretical knowledge + simulation practice + field practice", the "Internet +" entrepreneurship practice platform should be reasonably set up and constantly improved. When holding activities such as "challenge cup" entrepreneurship competition for college students and "Internet +" innovation, entrepreneurship and design competition, etc., information is exchanged, exchanged and Shared in real time with the help of Internet platforms. In addition, on the basis of making full use of information technology, the school can also constantly improve the network teaching system such as micro class, MOOC and maker, make full use of a large amount of information on the network platform, and improve the opening of innovation and entrepreneurship education courses by carrying out various theoretical teaching and entrepreneurship case teaching [4].

Simulative innovation entrepreneurship practice is created inside business incubation and entrepreneurship practice base, guide students to improve their professional ability training activities related to rely on the campus and college students' science and technology park, college students' innovative entrepreneurial practice base for students to walk out from the theory, through practice together now intelligence, knowledge, technology, capital, make the students of cooperation and innovation of science and technology innovation service platform; Relying on the cooperation of off-campus business incubation bases and various types of business centers, the company cooperates with enterprises to build simulated innovation and entrepreneurship platforms (such as factories and enterprises) and other actual combat places. Meanwhile, the effective resources of university alumni associations should be given full play to achieve "energy conservation and high yield". Let students feel the development process of the enterprise, and actually participate in the specific management and operation of the enterprise, so that teaching and social production are closely combined.

\section{F. Increase Government Policy Support and Encourage Participation by All Sectors of Society}

Innovation and entrepreneurship education is a major project that the whole society participates in. Only with the active guidance of the government, full efforts of colleges and universities, strong support from the society, and joint efforts of all parties, can we create positive conditions and create a good atmosphere for innovation and entrepreneurship education. The government policies, programs and other forms of support all social entrepreneurship, innovation in colleges and universities to carry out the policy, to provide hardware, software and technical support, make the classroom teaching and practical training, society, enterprise, industrial park, financial institutions, such as platform support, full participation, can effectively promote the further development of entrepreneurship education. At the same time, using alumni resources to carry out college innovation and entrepreneurship education, and achieve better results. 


\section{CONCLUSION}

To sum up, it is of great practical significance for the progress of education to strengthen the exploration of innovation and entrepreneurship education mode in colleges and universities under the background of "Internet + ". Relevant staff need to clarify the connotation and mode of "Internet + " and grasp the existing problems of innovation and entrepreneurship education in Chinese universities. On this basis, put forward under the background of "Internet +" points, innovative entrepreneurship education and development in colleges and universities set up the "+" Internet innovation entrepreneurship education new idea, perfect the "Internet + " entrepreneurship education courses, to enhance "Internet + " entrepreneurship education teachers team construction, improve the construction of the "Internet $+"$ entrepreneurship practice platform. Innovation and entrepreneurship education in the context of the Internet is a long-term and complex project [5]. As a national development strategy, it plays a positive role in promoting innovation and entrepreneurship education in colleges and universities, and has far-reaching significance for college students' employment and social and economic development. By constantly improving the innovation theory of entrepreneurship education system, and gradually construct the system of college students' innovative entrepreneurial education practice, integrating various resources, schools, enterprises and society to establish an open, diversified business practice platform and base, eventually to build a new innovative entrepreneurial education ideal mode - the government-led, the school as the main body, the society as a platform, knowledge-based entrepreneurial innovation entrepreneurship education system for the main business forms.

\section{CONFLICT OF INTEREST}

The authors declare no conflict of interest.

\section{AUTHOR CONTRIBUTIONS}

The first author Di Jiang, based on the project, conducted in-depth research, mainly responsible for the overall framework design and data analysis of the paper.

The second author Zhenlai Hou, was responsible for the investigation of the research status at home and abroad and the collation of documents.

\section{ACKNOWLEDGMENT}

Key project of the 13th five-year plan of education science in Jilin province - research on the construction of innovation and entrepreneurship course reform in colleges and universities based on the background of "Internet + education"(project on.ZD17089)

"13th five-year plan" social science research project of jilin provincial education department; Project title: study on the construction of a new mode of college innovation and entrepreneurship education under the background of revitalizing the northeast economy; Contract no. : JJKH20170283JY.

\section{REFERENCES}

[1] C. Huang and P. Li, "College students' employment entrepreneurship and "Internet+"," Journal of Shanxi University, 2015, vol. 27, pp. 73-76.

[2] S. Chen, "Research on problems and countermeasures of Internet innovation and entrepreneurship education for college students under the background of "new normal"," Management and Technology of Small and Medium-Sized Enterprises, 2015, vol. 11.

[3] Y. C. Zhang, "Research on innovation and entrepreneurship education mode of college students in the era of "Internet +"," Modern Communication, 2017, vol. 21.

[4] L. Li, "Research on talent cultivation mode of innovation and entrepreneurship education in colleges and universities under the background of "Internet +"," Audio-Visual Education in Primary and Secondary Schools.

[5] X. D. Liu, "Construction of new model of college students' innovation and entrepreneurship education in the era of "Internet +"," Journal of Higher Education, 2017, vol. 03.

Copyright (C) 2019 by the authors. This is an open access article distributed under the Creative Commons Attribution License which permits unrestricted use, distribution, and reproduction in any medium, provided the original work is properly cited (CC BY 4.0).

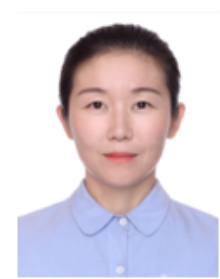

Di Jiang is CPC member. From September 2001 to July 2005, she studied in the Department of Psychology, University of North China; From September 2005 to July 2007, she studied in the School of Education Science, Northeast Normal University, majoring in applied psychology, and obtained the master's degree in education. The main research direction is college students mental health education and psychological counseling. After work, in December 2010, she participated in the psychological crisis special training for professor Nie Zhenwei of Beijing Normal University organized by Changchun University of Technology, and in August 2014, she participated in the teacher class training of SYB entrepreneurship course organized by Jilin Provincial Department of Human Resources and Social Security. In August 2015, she attended the training class for college counselors in Jilin province. In August 2016, participated in the jinggangshan ideological and political education practice training; Participated in the freshmen military training in 2010, 2011 and 2014, and won the title of excellent instructor; In December 2011, she participated in a series of training activities for counselors in Jilin University of Architecture and Engineering - themed class meeting design competition and won the second place. She is currently the office director and teaching secretary of the School of Municipal and Environmental Engineering.

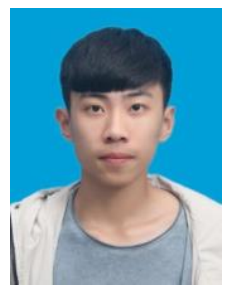

Zhenlai Hou was born on September 23, 1999, In September 2017, he majored in water supply and drainage science and engineering at Jilin Jianzhu University. 